\title{
El Hospital de Amor en la tradición hispánica: aproximación a los problemas de autoría
}

\section{The Hospital de Amor in the Hispanic Tradition: Approaching the Problems of Authorship}

\author{
José Vicente Salido López \\ Universidad de Castilla-La Mancha
}

\section{RESUMEN}

En el contexto de la poesía cancioneril de tema amoroso, la metáfora inspirada en el ámbito médico-hospitalario fue una de las más exitosas. Incluso dio para la recreación de universos alegóricos completos que tomaban como base al amor como causante de enfermedad. Es el caso del Hospital de Amor, un poema alegórico del que se nos han conservado cuatro versiones distintas - algunas firmadas-. El presente artículo pretende aproximarse al problema textual que plantea tal variedad de testimonios, entrando de paso en la cuestión de la autoría. La idea es partir del cotejo de las variantes y errores para tratar de fijar el hipotético stemma que subyace a estos testimonios, en un intento de búsqueda de la versión más próxima al original.

Palabras Clave: Literatura alegórica, lírica medieval, cancioneros, amor hereos, hospital de enamorados, Juan Boscán, Luis Hurtado de Toledo, Licenciado Ximénez.

\begin{abstract}
The metaphor inspired in the medical and hospital topic was one of the most successful within the context of medieval poetry love theme. A proof of the importance of this metaphor is that it was even used to recreate allegorical universes whose base was love as origin of disease. This is the case of the Hospital de Amor, an allegorical poem of which four different versions have been kept, some of them signed. This article attempts to approach the textual problem caused by such a variety of texts, and at the same time addresses the matter of authorship. The objective of the study is to establish the hypothetical stemma that underlies the four different versions by comparing variant and mistakes, and doing so, find the the most faithful version of the text.
\end{abstract}

Key words: Allegorical literature, medieval lyric, poetic anthology, lovesickness, hospital for lovers, Juan Boscán, Luis Hurtado de Toledo, Licenciado Ximénez. 


\section{LA PROBLEMÁTICA AUTORÍA}

Una de las metáforas amorosas que más fortuna tuvo en la tradición de la lírica cancioneril fue la inspirada en el ámbito médico. El hecho de que desde la misma medicina el enamoramiento obsesivo fuera tratado como enfermedad mental que alteraba los humores de los que lo padecían, el llamado amor hereos, facilitó el vuelco semántico en la construcción de la metáfora. Términos como dolor, accidente ('enfermedad o indisposición temporal'), mal de amor, ansia, cición ('fiebre, calentura'), cura ('cuidado, tratamiento médico'), desmayo, desvarío ('locura'), dieta ('régimen de enfermo'), dolencia, doliente ('enfermo'), malenconía ('melancolía'), físico ('médico'), heridas de amor, enfecionar, salud, unción ('aplicación de untura medicinal'), botica, basca, xarope ('jarabe')... están documentados con acepciones relacionadas con lo sentimental en las diversas ediciones antiguas del Cancionero general de Hernando del Castillo ${ }^{1}$, por citar una de las colecciones más nutridas de lírica castellana; pero los ejemplos en cualquier compilación de este tipo son, por regla general, abundantes.

En un paso más, el gusto por esta metáfora dio frutos más elaborados, con poemas que recreaban todo un universo alegórico montado en torno al Amor como causante de enfermedad; es el caso del Hospital de Amor, un poema que cuenta la llegada de un enfermo a un hospital que el propio Amor había fundado para los que sufrían sus males. A la llegada del protagonista lo reciben otros personajes alegóricos como el Cuidado, que ejerce de hospitalero, o el Tiempo, la evidente representación alegórica del médico que cura las penas de amor. Junto a estos inicia la visita para conocer el estado de los enfermos internos —en total, nueve-, todos ellos llagados de diferentes dolencias derivadas del enamoramiento. Tras la visita, el poema termina con el ingreso del protagonista, en un principio desahuciado, aunque queda aferrado a la esperanza que le da una carta que envía a la amada pidiéndole correspondencia amorosa, la única solución para sus males.

No se trata de un producto aislado, sino del resultado de una tradición literaria extensa que generó una serie de topoi a partir de la asimilación del amor entendido como patología. Las muestras de este motivo son muy amplias $^{2}$, pero los antecedentes más claros del texto que nos ocupa están en

${ }^{1}$ Hasta nueve ediciones antiguas conoció el Cancionero general de Castillo: Valencia: Cristóbal Koffman, 1511; Valencia: Jorge Costilla, 1514; Toledo: Juan de Villaquirán, 1517 y 1520; Toledo: Ramón de Petras, 1527; Sevilla: Juan Cromberger, 1535 y 1540; Amberes: Martín Nucio, 1557; Amberes: Felipe Nucio, 1573. Para las ediciones modernas del Cancionero de Castillo, véase Salido López (2009). Remitimos al glosario de la edición más reciente, la que está al cuidado de Joaquín González Cuenca (Castillo, 2004: V, 103-411), para la documentación de los términos referidos y su localización en el corpus poético.

${ }^{2}$ La visión del enamorado como enfermo era algo perfectamente asumido desde planteamientos teológicos, médicos y sociales (Whinnom, 1991: 9-15), y su presencia en la lite- 
moldes alegóricos que coinciden en la concepción del amor como causa de sufrimiento. El referente más próximo lo encontramos en los infiernos de enamorados que proliferaron con relativa frecuencia en la poesía cancioneril. Pérez Priego (2002: 310-320), que ha estudiado los de la tradición castella$\mathrm{na}^{3}$, reconoce en el modelo la herencia de Virgilio y de Dante. De ellos procede buena parte de las características que configuran el género, como la salida desesperada del protagonista en busca de consuelo, el locus horridus que sirve de marco a la acción o el viaje guiado por el universo alegórico. En cuanto a los personajes, los condenados de estos infiernos generalmente son los protagonistas de los episodios amorosos más célebres, entre los que no falta Macías. Su tormento se manifiesta en llagas y heridas físicas que son símbolo del padecimiento del enamorado, modalidad de sufrimiento que en sentido estricto no es una adaptación literaria del amor hereos pero que se acerca mucho a la imagen del mal de amores que se desarrolla en el Hospital.

Así pues, el Hospital de Amor es una manifestación perfectamente integrada en la tradición de la lírica cancioneril castellana, a pesar de ser una producción tardía de esta corriente literaria ${ }^{4}$. Pero esto no significa que fuera

ratura como recurso hiperbólico se rastrea en un buen número de obras medievales. Se escapa de los límites del presente estudio un análisis minucioso de la presencia del amor hereos en nuestra literatura medieval. El tema ya ha sido estudiado, por ejemplo, para el caso del Libro de buen amor (Amasuno, 2004), de La Celestina (Amasuno, 2000a; Amasuno, 2000b; Armas, 1975; Beltrán, 1988; Castells, 1993; Cátedra, 1989: 57-84; Lacarra, 1999; Lacarra, 2001; Lacarra, 2007; Martin, 1972; Morros, 2009; Porras, 2008; y Šabec, 2012, entre otros; y como contexto sobre las teorías médicas sobre el amor en la época de Fernando de Rojas, Cátedra, 2001), del género caballeresco (Lobato, 2012) o de la Cárcel de Amor (Whinnom, 1991), donde también encontramos el motivo de la carta que el protagonista envía a través de un emisario para ganar la correspondencia amorosa de la dama. A ellos remitimos a quien busque noticias más precisas sobre el asunto.

${ }^{3}$ En su estudio, Pérez Priego hace un repaso de las diferentes manifestaciones de este género en nuestra literatura, presentando una visión panorámica que ayuda a extraer la esencia de la fórmula alegórica. Comienza su análisis con el testimonio más antiguo que conocemos, el Infierno de los enamorados del Marqués de Santillana (1999: 289-320), compuesto hacia 1440 e incluido en el Cancionero de Estúniga (1987). Después de él, García de Pedraza, con su decir alegórico recopilado en el Cancionero de Palacio (1993), Juan de Andújar con su composición que se inicia con «Como procede Fortuna», también recogida en el Cancionero de Estúñiga, y Guevara y Garci Sánchez de Badajoz con sendos poemas publicados en el Cancionero general - aunque en sentido estricto el infierno de Guevara no sea un viaje alegórico como el resto de ejemplos, sino una metáfora del sufrimiento del enamorado- son otros de los autores que se sirven de este patrón. También tiene en cuenta otro caso muy próximo a estos infiernos, incluso en lo conceptual; nos referimos al Purgatorio de Amor del Bachiller Ximénez, publicado en el Cancionero general de 1511.

${ }^{4}$ Como veremos a continuación, hay dudas sobre la datación de alguno de los testimonios conservados, pero aun tomando como referencia la fecha más temprana que se ha manejado, nos situaríamos en torno a 1535 , cuando ya las fórmulas italianas han empezado a ganar terreno a las de la tradición castellana. Los testimonios impresos se fechan en 1557; a estas alturas las recopilaciones poéticas dedican ya buena parte de sus páginas a composi- 
un producto desfasado; de hecho, debió de tener relativo éxito a juzgar por los múltiples testimonios que se nos han conservado. En total son cuatro, dos impresos y dos manuscritos ${ }^{5}$. Uno de ellos se encuentra dentro de las Cortes

ciones en metros italianos (Prieto, 1991: 49-50). Que por esas fechas aún se emplee este texto como novedad editorial en, por ejemplo, el Cancionero general es prueba de la vitalidad de la fórmula todavía en la segunda mitad del siglo XVI.

${ }^{5}$ La canción dialogada para desposorios que abre el Cancionero llamado Dança de galanes (Barcelona: Jerónimo Margarit, 1625), de Diego de Vera, recoge unas coplas que calcan la alegoría del Hospital de Amor y que, además, incluyen versos literales del poema. No tenemos noticia de que ningún estudio dedicado al asunto haga mención de ellas. Aquí no las tomaremos en cuenta para trazar la hipótesis ecdótica del texto por lo fragmentario del testimonio, pero queremos dejar constancia de su existencia por ser síntoma inequívoco de la amplia difusión de que gozó el poema y de su asimilación como elemento de condición popular. Estas son las coplas:

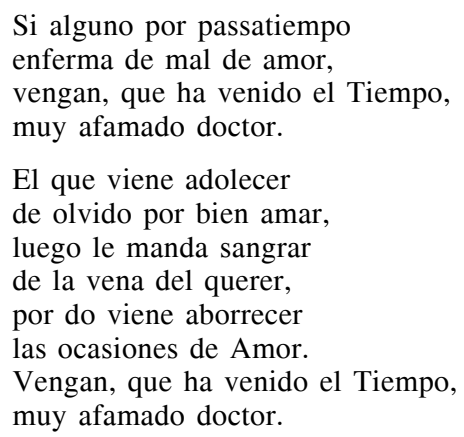

Vengan todos, porque veo que da muy buen regimiento; da al enfermo de desseo tabletas de sufrimiento. Múdales el pensamiento adonde tenga favor en el conveniente Tiempo, muy afamado doctor.

$\mathrm{Y}$ al que por algunas vías adolecense los graves, luego le ordenan xaraves por purgar las fantasías. Y con esto, en pocos días está sano y muy mejor. Vengan, que ha venido el Tiempo, muy afamado doctor.

RESPONDE EL GALÁN

¡Quién dirá la enfermedad que yo siento y mi dolor, si por sanar, al doctor tengo de dezir verdad! 
de Casto Amor y Cortes de la Muerte, una miscelánea aparecida en 1557 en el taller toledano de Juan Ferrer y compuesta por una serie de obras, en prosa y verso, firmadas por Luis Hurtado de Toledo. Entre ellas se incluye este poema con el título Hospital de galanes enamorados ${ }^{6}$.

También de ese mismo año de 1557 es otra versión de este poema algo diferente en algunos momentos pero claramente relacionada con la que publicó Hurtado a su nombre (en adelante $T$ ). Se encuentra entre las novedades incluidas en la edición del Cancionero general de Hernando del Castillo impresa en Amberes, Martín Nucio, 1557, bajo el título de Hospital de Amor (A) y sin nombre de autor ${ }^{7}$. El que apareciera sin firma tiene que ver con el criterio que siguió el editor de no informar de la autoría en el medio centenar de poemas que incorporó de nuevas al Cancionero general ${ }^{8}$. Pero no puede darse por hecho que el nombre de autor que se omite en el Cancionero general sea el de Luis Hurtado porque a mediados del siglo pasado salió a la luz un manuscrito que se había conservado en los fondos de la Biblioteca Nacional de Cataluña con obras atribuidas a Boscán entre las que se incluía un Ospital de Amor $(B)^{9}$.

\author{
Que a mí el mal que vino \\ fue el mirar por cierta vía \\ y assentó en la fantasía \\ hasta sacarme de tino. \\ Procediome de un dolor, \\ pero que digo es maldad \\ si al médico o al doctor \\ tengo de dezir verdad (ff. b8v-b9v).
}

${ }^{6}$ El volumen incluye las Cortes de Casto Amor (ff. 4v.-20r), el Coloquio de la prueva de leales (ff. 20v-24v), el Hospital de galanes enamorados (ff. 25r-31r), el Hospital de damas de Amor heridas (ff. 31v-38r), el Espejo de gentileza para damas (ff. 38r-45r), la Fición deleitosa y triumpho de Amor (ff. 45v-58r), tres epístolas y unas líneas del autor a una dama (ff. 58v-62r) y con portada propia y foliación independiente las Cortes de la Muerte (ff. 168r). Hay edición facsimilar de la obra (Valencia: Andrés Ortega del Álamo y Librería Bonaire, 1964) con estudio introductorio de Antonio Rodríguez-Moñino, al que acudiremos en alguna ocasión más (Rodríguez-Moñino, 1964).

${ }^{7}$ Aparece en los ff. 352r-356r de las ediciones de Amberes: Martín Nucio, 1557 y de la de Amberes: Felipe Nucio, 1573, las dos últimas ediciones antiguas del Cancionero general. Para las ediciones modernas del texto, véase Castillo (1959: 229-236); Castillo (2004: IV, 643-663); y Wunster (1991: 75-115).

${ }^{8}$ La causa de este anonimato generalizado entre las composiciones incluidas en esta edición del Cancionero general probablemente tuvo que ver con que alrededor de una treintena de ellas eran obras que, por su tono antimatrimonial, reflejaban el desagrado que cundió en el ambiente social de la época por la boda de conveniencia del por entonces príncipe Felipe, el que llegara a ser Felipe II, con su tía, María Tudor. El carácter reaccionario de estos textos pudo ser la causa que llevó al editor a no dar el nombre de los autores, haciendo extensible este criterio a la otra veintena de poemas de diversa temática (González Cuenca, 2004: 74-75).

${ }^{9}$ Concretamente, este Hospital de Amor se encuentra en los ff. $19 \mathrm{v}-35 \mathrm{r}$ del ms. 359 de la Biblioteca Nacional de Cataluña. Martín de Riquer lo publica por primera vez en 1942 y vuelve a él con más profundidad tres años después (Riquer, 1942 y 1945). El códice es una 
Era otra versión más de ese mismo poema que imprimió como suyo Hurtado y que, curiosamente, guarda puntos de encuentro mucho más evidentes con $T$ que los que se dan entre $T$ y la anónima del Cancionero general ${ }^{10}$. Es decir, precisamente las dos versiones que aparecen atribuidas son las más similares entre sí, lo que supone no poder dar como seguro el nombre de un autor para la versión del Cancionero general, porque cualquiera de los dos poetas (si es que no fue otro distinto a ellos) pudo haber sido el autor.

Por último, en otro manuscrito de finales del siglo XVI o principios del XVII conservado en la Biblioteca Nacional de España que contiene una suerte de miscelánea de textos literarios y crónicas de sucesos reunida por Gabriel de Peralta ${ }^{11}$, aparece un Hospital de Amor $(M)$ sin nombre de autor, algo más breve que los otros tres testimonios pero muy próximo también a la versión de $T^{12}$.

Además, la cuestión se complica más porque, aparte de la variedad textual ${ }^{13}$, contamos con una atribución indirecta que mete un candidato más en discordia. En el Discurso de Pedro de Cáceres que aparece al frente de las Obras de Gregorio Silvestre, publicadas en 1582, cuando habla del Licencia-

copia hecha por una mano catalana que Rodríguez-Moñino se atreve a fechar hacia el año 1570 (1964: 17); Clavería (Boscán, 1999b: 28) discuerda en la datación y lo fecha en 1535. Para la edición crítica del poema, véase Riquer (1945: 95-118); Vega y Boscán (1964: 623646); Boscán (1991: 115-135); Boscán (1995: 520-538); Boscán (1999a: 583-603); Boscán (1999b: 432-452); Boscán (2010: 406-422); y Wunster (1991: 75-115).

${ }^{10}$ A la misma conclusión llegó Rodríguez-Moñino (1964: 16-17) a partir del análisis comparativo de las tres versiones. Como explicaremos más adelante, únicamente diferimos en su idea de que sea la barcelonesa una versión deturpada y mutilada de la que firma Hurtado; hay más razones para defender una hipotética transmisión activa del texto original por parte del autor toledano.

${ }^{11}$ El manuscrito consta de 166 folios, de los que hasta el f. 158r son obra de Gabriel de Peralta. En el vuelto de este folio aparece una nota con letra distinta que dice «Este libro dejó todo escrito de su mano mi padre y señor Gabriel de Peralta, que falleçió a 10 días del mes de setiembre de 1625 años». De ahí hasta el final — la última entrada que se hizo data de la década de 1670 - fueron varias las manos que intervinieron.

${ }^{12}$ Se trata del ms. 4072 de la Biblioteca Nacional de España. En los ff. 6r-9r aparece este poema con el encabezamiento Hospital de amor. Para más detalle sobre el manuscrito, véase Jauralde (1998: III, 1678-1692). Nider (2001: 928) señaló con acierto la relación de este texto con los otros tres ya conocidos. Pone enmienda al error de Clavería en su edición de las obras de Boscán (1991: 134-135), que lo descarta como testimonio a considerar en el estudio textual del poema alegando una inexistente distancia con las otras versiones.

${ }^{13}$ También en la tradición francesa se documenta un Hôpital d'Amour firmado por Achille Caulier y fechado hacia 1441, pero, como demostró Wunster (1991), no está relacionado directamente con ninguna de las versiones del Hospital de Amor español, aunque guarda con él notables similitudes que son consecuencia de una tradición alegórica compartida. Nider (2001: 927) también refiere determinados textos cancioneriles portugueses que comparten algunas características, fundamentalmente estructurales, con los hospitales castellanos. En este sentido, podría haber sido perfectamente asumible la idea de que los cuatro testimonios conservados en nuestra tradición son manifestaciones de una moda literaria de la que participaron otros tantos, pero basta una comparación a vuela pluma para descartar esta hipótesis por la evidente filiación entre ellos. 
do Ximénez, predecesor de Silvestre en el oficio de organista de la catedral de Granada, y de unos entremeses suyos hechos para esa catedral, afirma que también «hizo el Hospital de amor que imprimió por suyo Luis Hurtado de Toledo» (Rodríguez-Moñino, 1964: 16).

Ciertamente, basta un repaso de la obra de Luis Hurtado para ver la frecuencia con la que el párroco toledano puso su pluma en obras ajenas para realizar leves aportaciones que lo autorizaron para firmarlas como propias. Así, por ejemplo, su nombre sonó como posible autor del Palmerín de Inglaterra ${ }^{14}$, una de las pocas novelas de caballerías salvadas en el famoso escrutinio del Quijote, porque en unas coplas puestas al frente de la edición castellana de la novela aparecían unos versos acrósticos que codificaban el mensaje Lvys Hvrtado avtor al lector da salvds. Sin embargo, son muchos los indicios que llevan a pensar que, en el mejor de los casos, su aportación no fue más allá de la corrección del texto o, como mucho, de la traducción de la versión portuguesa. También fue escasa su participación en la Comedia Tibalda, obra de Perálvarez de Ayllón que apareció en 1553 en las prensas toledanas de Juan Ferrer con un prólogo de Hurtado en el que reconoce haberla rematado porque su verdadero autor murió sin finalizarla; el hallazgo de un manuscrito con la versión primitiva de la obra permitió comprobar que su aportación fue prácticamente anecdótica (Serís, 1930: 507-533). En el título de las tres epístolas incluidas en el volumen de las Cortes de Casto Amor avisa de que están compuestas por «un moro en Granada, por Adamira» y que él las ha contrahecho en sentido espiritual. Aunque suena a ficción literaria, hay indicios que apuntan a don Manuel de Portugal y a Gutierre de Cetina como posibles autores de, al menos, dos de ellas (Greco, 1977: 151). Y un caso parecido se comprueba en las Cortes de la Muerte, que, como reconoce el propio Hurtado en el prólogo, «fueron començadas por Michael de Carvajal, natural de Plazencia, y agradando tal estilo, yo las proseguí y acabé» ${ }^{15}$. Por último, también es evidente la deuda de su Espejo de gentileza para damas y galanes con el Doctrinal de gentileza de Hernando de Ludueña, al que llega a seguir al pie de la letra en algunos puntos (Ludueña, 1998: 62-63).

Estos antecedentes serían razones de relativo peso para negarle a Hurtado la autoría del Hospital de Amor que dio pie al resto de versiones. Pero hay algún indicio más que se nos ofrece en el análisis contrastivo de las distintas

${ }^{14}$ Algunos de los estudios clásicos dedicados a la polémica sobre la autoría del Palmerín son Mendes (1860); Salvá (1829: 29-74); Clemencín (1833-1839: I, 1, 124-128); Díaz de Benjumea (1860); Gayangos (1862); Purser (1904); Michäelis de Vasconcellos (1881: 5, 216255, y 1882: 6, 37-63). Para una panorámica general de lo que fue la polémica y de las principales aportaciones que la desarrollaron, véase la «Introducción» de Aurelio Vargas DíazToledo a Moraes (2006: X-XVII).

${ }^{15}$ Para una panorámica general de la polémica y de las opiniones de la crítica sobre el grado de implicación de Hurtado en las Cortes de la Muerte véase Irisarri (1990, I, 7-ss.); Rodríguez-Moñino (1964: 18); y Crawford (1922: 150). 
versiones y que lleva a pensar que, definitivamente, esa merecida fama de refundidor de Hurtado se vuelve a comprobar en este caso. Por eso, diferimos de la idea de Rodríguez-Moñino, que se detuvo en el análisis comparativo de las versiones de $T$ y $B$, las dos que más puntos de encuentro tienen entre sí, y concluía lo siguiente:

Escasas diferencias hay entre la lección barcelonesa y la que ofrece Luis Hurtado, todas en perjuicio de aquélla, puesto que se limitan a la supresión de ocho estrofas y una canción final. Por lo demás, alteraciones que más parecen cosa de copista indocto que derivadas de diferente redacción (Rodríguez-Moñino, 1964: 17).

Efectivamente, las muestras de consanguinidad entre las dos versiones son claras y la descuidada labor del copista de la versión manuscrita de Barcelona es un hecho. Pero en lo relativo a las supresiones, quizás habría que reconsiderar la teoría de Rodríguez-Moñino, porque con seguridad Luis Hurtado no es el autor de la versión original del poema. Ello significa que esas coplas que no aparecen en $B$ probablemente no fueran supresiones del copista, sino licencias poéticas que se permitió Hurtado.

Hay un punto concreto en el que se observa con claridad que Luis Hurtado intervino en un texto que no le era propio. Se encuentra en el verso 102 de $T$, donde se recoge una curiosa variante con respecto a $A$ y $B$, los otros dos testimonios que contienen esa copla. A esa altura, tanto en el manuscrito barcelonés como en la versión del Cancionero general aparece: «Respondí: «Padre señor, / yo soy un desventurado». La versión de Luis Hurtado presenta una lectio singularis que dice: «Respondí: «Padre señor, / soy de libertad hurtado», con una evidente modificación del párroco toledano de la que a todas luces es la versión original para jugar con su apellido. Si $T$ fuera la versión original del texto, lo normal es que la adiáfora «hurtado» se hubiera mantenido en los otros testimonios y no precisamente en el único que tiene la firma de Luis Hurtado, lo que hace pensar que, de nuevo aquí, el poeta toledano se sirvió de un texto ajeno para componer su Hospital de galanes. De hecho, como bien ha visto Nider (2001: 932), no es esta la única ocasión en la que el poeta toledano emplea estas claves o «senhales», de clara tradición trovadoresca; también aparecen en alguna de las obras que dedicó a la familia de los Vargas Manrique.

Además de esto, el análisis ecdótico de las cuatro versiones aporta una razón más para negarle la autoría original del Hospital a Hurtado. La lectura comparativa de los testimonios no revela errores conjuntivos evidentes que ayuden a plantear la relación textual entre las versiones pero delata una anomalía en la estructura de una copla que es común a dos testimonios y que puede tener categoría de error. Este caso se encuentra a la altura de la estrofa LVIII de $B$, en el punto en el que el médico recomienda al protagonista como única salvación para su vida que envíe un emisario solicitando correspondencia amorosa a la dama: 
[LVIII] Con éste as de enviar

a la que te cativó

a dezir de tu penar,

y que si ella sola no,

nadi vasta a remediar (vv. 571-575).

A esa misma altura, $A$, que por sistema ofrece la versión más original si tomamos como referencia el resto de testimonios, presenta una quintilla notablemente diferente, pero que contiene en esencia la misma idea:

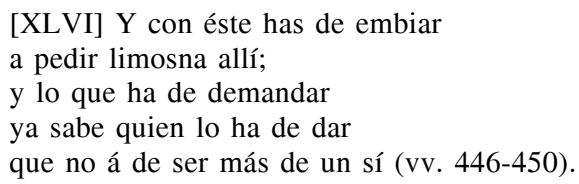

En $T$ y $M$ se produce un fenómeno curioso, porque presentan unidas en una misma copla real esas dos quintillas que son equivalentes en $A$ y $B$ :

\section{$T$}

[LXII] Con aqueste as de embiar

a la que te cativó

a dezille tu penar

y que, si ella sola no,

nadie basta a remediar;

y con éste as de embiar

a pedir limosna allí,

y lo que á de demandar

ya sabe quien lo á de dar

que no á de ser más de un «sí».

(vv. 611-620)
M

[XXXIII] Con aqueste as de embiar

a la que te captivó

a dezille tu penar

y que, si ella sola no,

nadie basta a remediar;

vaya luego sin tardar

a pedir limosna allí.

y lo que á de demandar

sepa la que lo á de dar

que no á de ser más de un «sí».

(vv. 321-330)

El que esta copla real es fruto de la intervención de un copista que contaminó su versión manejando varios testimonios con las versiones de $B$ y de $A$ es una hipótesis que casi se confirma en las diversas anomalías que presenta la estrofa. Por ejemplo, la inevitable redundancia que provoca el que las dos quintillas no sean más que una reformulación de la misma idea es un detalle evidente, sobre todo en $T$, que incluso repite el mismo verso al inicio de cada quintilla. El copista de $M$ debió de detectar la irregularidad que provocaba la repetición del verso y por eso modificó la segunda quintilla iniciándola con un «vaya luego sin tardar», en un intento por disimular la anómala redundancia de la copla. También es significativo el que la estructura de la segunda quintilla, la que procede de $A$, conserve el mismo patrón de rima en abaab. La estrofa habitual que se emplea en el Hospital de Amor es la copla real formada por dos quintillas rimando en ababacdcdc. Solo ocasionalmente, y de forma más frecuente en $A$, este patrón de rima se altera para presentar quintillas con pareado rimando en aabba o abaab, como ocurre precisamente en 
este caso, donde $A$ ofrece este esquema menos habitual que, curiosamente, repiten $T$ y $M$. Por último, también es llamativo el hecho de que esta copla solo tenga tres rimas, en lugar de las cuatro que por sistema tiene el resto de estrofas del poema ${ }^{16}$. Todas estas anomalías llevan a pensar en esa posible contaminación de testimonios a la que se le puede dar rango de error conjuntivo entre $T$ y $M$.

A pesar de que $M$ es un testimonio más tardío que $T$, por lo que no sería raro que el impreso de $T$ hubiera sido manejado por el copista de $M$, no se puede establecer una relación de filiación directa entre ambos a la hora de explicar el origen de este error conjuntivo. La razón es que $T$ solamente tiene un error en los versos que comparte con $M$ y ese error no aparece en este testimonio manuscrito; está en el verso 456 de $T$, donde dice «El mal que siento / no basta lengua ni pluma», en lugar de «Al mal que siento / no basta lengua ni pluma», lección que aparece en $M$ y $B$, los otros dos testimonios que contienen el pasaje. Y aunque podría tratarse de una intervención del copista de $M$ para corregir el verso deturpado de $T$, esta hipótesis queda descartada porque $M$ presenta determinadas lecciones compartidas con $A$ y $B$ frente a $T^{17}$, lo que significa que esas adiáforas de $T$ son licencias que introdujo Hurtado en su versión apartándose del modelo que empleó para su Hospital y que habrían llegado a $M$ si $T$ hubiera sido su fuente. Por ello hay que suponer la existencia de un subarquetipo perdido del que proceden ambos testimonios. Ese subarquetipo es el que debió de contaminarse con la versión de la rama de $A$ para crear esa copla híbrida que acabamos de tratar como error conjuntivo de $T$ y $M$.

Se demuestra así que $T$ es copia de un subarquetipo, lo que supone descartar a Hurtado de la lista de posibles autores del texto que inspiró las distintas versiones del poema. Igualmente, esas supresiones que RodríguezMoñino achacaba a la labor torpe del copista de $B$ habría que considerarlas añadidos que $T$ aporta a su fuente. Concretamente, la mano de Hurtado sería la responsable de la corrección de algún error (si es que llegó a tanto), de irrelevantes alteraciones (si es que proceden de su mano y no de la versión que le sirvió de base), del prólogo en prosa $^{18}$, de las coplas XVIII-XX, LIV y LXXI-LXXII y de la canción final, las únicas partes que $T$ no comparte con

${ }^{16}$ Esta anomalía solamente se repite una vez más en todo el poema, en la copla XIII de $T$ (M: om.; A: XII-XIII; $B$ : XIII).

${ }^{17}$ Estos casos se encuentran en el v. 286 de $T$ («Mas con éste as menester»; M: v. 46 «Mas con esto as menester»; A: v. 251: «y, con esto, has menester»; B: v. 256: «Mas con esto es menester»), en el v. 417 («las lágrimas de los ojos»; $M$ : v. 167; B: v. 387: «las lágrimas de sus ojos»; A: om.), en el v. 635 («llegava que no cargado», $M:$ v. 335; B: v. 585 : «venía que no cargado»; A: v. 464: «de penas vengo cargado») y en el v. 663 («y dezid de cómo ya»; $M$ : v. 368; $A$ : v. 498: «a dezirle cómo ya»; $B$ : om.).

${ }^{18}$ Este prólogo es muy similar en lo esencial al que puso al frente de la Comedia de Preteo y Tibaldo (1553), otra obra ajena en la que actúa de manera similar. 
ninguno de los otros testimonios. Y esos pocos arreglos debieron de servirle para verse en el derecho de adjudicarse la autoría del poema.

Según estas conclusiones, tampoco pudo ser $M$ la versión original. Consta de treinta y ocho estrofas que se centran únicamente en la visita del médico a los distintos enfermos de amor. El hecho de ser más breve podría llevar a pensar que esta versión pudo ser la original y el resto de testimonios sean ampliaciones compuestas a partir de esta. No obstante, aparte de las razones textuales ya alegadas, hay otras que invitan a rechazar esa hipótesis. Y es que las coplas XXX-XXXVIII, con las que se remata esta versión, aluden a la enfermedad del protagonista sin haber presentado previamente al lector el contexto que explica el porqué de su enfermedad, de su llegada al hospital y de la visita que hace a los otros enfermos de amor. Esa estructura argumental incompleta hace suponer que las partes que no aparecen en esta versión no son añadidos del resto de versiones, sino omisiones del copista que transcribió este testimonio.

Esto es lo único seguro que se extrae del análisis comparativo de los cuatro testimonios. A partir de aquí sólo se pueden plantear conjeturas para intentar trazar el hipotético stemma del texto. Por ejemplo, es muy probable que esa contaminación de la rama de $T$ y $M$ de la que venimos hablando no se produjera directamente con $A$ por una cuestión estrictamente cronológica. $A$ se publica en 1557 — no se tiene noticia del día y mes- y $T$ aparece el 15 de octubre de ese mismo año. Es decir, para que $A$ pudiera ser la fuente de contaminación de $T$, necesariamente debería haberse publicado antes de ese mes, y aun así, los pocos meses que pudieron separar ambas publicaciones se antojan escasos para completar el proceso de contaminación desde $A$ a $T$, pasando por un subarquetipo perdido. Por eso habría que suponer que el testimonio que manejó el copista del subarquetipo fue algún testimonio manuscrito que sirvió para componer el impreso de $A$.

De este testimonio, lo más interesante es que presenta la versión que más se aparta del modelo que siguen los otros tres textos, a pesar de que es evidente que procede de la misma fuente que $T, M$ y $B$. Con $B$ comparte el título y determinadas lecciones en las que $T$ y $M$ se desmarcan. Y con $T$ y $M$ también presenta algunas coincidencias que se separan de $B$, hecho explicable porque, como veremos, el copista de $B$ también incluyó aportaciones personales al texto. Por lo demás, el Hospital de Amor del Cancionero general se limita a suprimir algunas quintillas sueltas y quince estrofas y media que cuentan la visita a cinco de los nueve enfermos de amor. Varía notablemente algunas estrofas y añade otras nuevas, entre las que se encuentran seis coplas reales y una quintilla suelta en las que se desarrolla la carta que el enamorado envía a la dama y que en las otras tres versiones únicamente aparece mencionada.

Da la impresión de que se trata de una versión con un carácter decididamente dramático que atiende más a lo puramente lírico que a lo alegórico, con 
un léxico que incide en lo sentimental, buscando en ocasiones un matiz teatral, casi patético ${ }^{19}$, y una adjetivación mucho más rica que la de las otras versiones. Todas estas modificaciones parecen responder a un interés por modernizar un texto que ya había quedado desfasado a la altura de 1557, cuando se incorpora al Cancionero de Castillo, en un ambiente en el que las formas poéticas italianas se habían impuesto a las tradicionales castellanas.

Monica von Wunster, que estudió con detenimiento la relación de esta versión del Cancionero general con la atribuida a Boscán, no opina así. Partiendo de la idea de que ambas versiones procedían de la mano del poeta catalán, concluye que $A$ bien pudo ser una versión de juventud que modernizó en $B$ quitando elementos pasados de moda, como la carta dirigida a la dama (Wunster, 1991: 69-70). Sin embargo, hay indicios que llevan a pensar justo lo contrario. El primero es que $A$ presenta la versión más distinta con respecto a los otros testimonios conservados, lo que permite suponer que no ofrece la versión original, sino un texto plagado de licencias poéticas de un autor que modificó a su gusto la versión empleada como fuente. Y aunque esto pudiera deberse a que los otros tres testimonios proceden de un subarquetipo común - hipótesis que no se puede demostrar con los datos de que disponemos-, que sería el que se apartó de la versión original, el estudio de la estructura de las cuatro versiones permite descartar esta posibilidad. Estructuralmente, $A$ presenta dos variaciones fundamentales con respecto a los otros testimonios: la inclusión de la carta y la supresión en bloque de la visita a los últimos cinco enfermos. El desarrollo de la carta del enamorado, que en las otras versiones solamente aparece mencionada, parece estar motivado por ese interés por lo lírico que comentábamos unas líneas atrás, porque en ella se profundiza con más detalle en el sentimiento de angustia del protagonista. Por su parte, la supresión de las cinco últimas visitas seguramente está relacionada con la intención de aligerar el poema, metiendo la tijera precisamente en su parte más tediosa. Pero con ello, de forma consciente o no, se destruye buena parte del universo alegórico que es la base del poema. El que fueran nueve los enfermos que se visitan no era una cuestión aleatoria; el número nueve encerraba un simbolismo que tenía que ver con la totalidad — nueve, por ejemplo, eran los cielos que completaban el orbe en las antiguas teorías astronómicas- y que se había empleado en otros viajes alegóricos como el de la Divina comedia (Chevarlier y Gheerbrant, 1982: 663-665). Los nueve enfermos de este hospital conforman un universo alegórico completo y perfecto hecho a imitación del Universo ideado por Dios para su Creación. Nider (2001: 929) incluso alega argumentos estructurales y métricos para justificar la presencia de precisamente nueve enfermos:

${ }^{19}$ Para llegar a esta conclusión es muy significativa la adiáfora que presenta $A$ en los versos que dicen «Señora, si en vos no hay fe / no me detengáis biviendo / porque yo me ahorcaré» (vv. 53-55), frente al «que por muerto me tendré» de $T$ (v. 60) o «del morir me socorré» de $B$ (v. 60). 
Este número, pues, no parece ser gratuito, sino que parece tener correspondencia hasta con la estructura métrica, ya que el yo poético, al final de la visita, declara al médico sus propias enfermedades, con miedo de tenerlas todas, citando todos los casos precedentes en una única estrofa:

Que yo muero de deseo

y bivo menospreciado,

y también celos poeso,

estando más olvidado

cuando más privar me creo,

buelo en alto sin que buele

y es mi engaño muy crescido,

y aun el coraçón me duele,

la presencia me ha herido,

y crüeza como suele (Galanes, vv. 561-570).

Por tanto, hay razones suficientes para suponer que esta versión de cuatro enfermos que presenta $A$ no es más que una reducción de lo que pudo ser el texto original realizada con el fin de hacer más ligero el poema y adaptarlo a gustos más modernos ${ }^{20}$.

Falta por ver las conclusiones que afectan a $B$, una copia de mediados del siglo XVI, obra de un copista catalán que también se permitió determinadas licencias en la transmisión del texto original. Así lo demuestran las tachaduras que conserva el manuscrito, debajo de las cuales se intuye la lección que aparece en los otros testimonios. Por ejemplo, en el v. 299 de $T$ aparece «de ver más favorecido», la misma lección que en $A$, el otro testimonio que contiene el verso. En cambio, $B$ ofrece la variante «de ver de ser más amado», aunque se puede ver tachado «de ver más favorecido». Sin duda, ese verso es obra del copista, quien, tras haber variado la palabra en rima del v. 297, escribiendo «cuitado» en vez del «afligido» de las otras dos versiones, tiene que rehacer este verso al darse cuenta de la falta de rima. Es significativo de la intencionalidad de su intervención el que en vez de tachar la palabra de rima que ocasiona el desajuste se atreva a componer un verso entero, aun a costa

\footnotetext{
${ }^{20}$ Coincidimos, pues, con Valentina Nider al considerar incompleta la estructura de $A$, aunque no con su explicación de tal desajuste estructural. Para Nider, la estructura de $T, M$ y $B$ pretende aligerar el dramatismo del asunto ampliando la casuística amorosa: «En la versión del Cancionero general, donde se encuentran tan sólo cuatro dolientes (de deseo, de desdén, de celos y de olvido), no hay esta correspondencia y el yo poético declara sufrir de deseo y de celos y, sobre todo, coherentemente con su visión de la dama como cruel e inalcanzable, dedica toda una estrofa a la valoración de su "poco merecimiento», pues por más que intente elevarse «nunca le podré alcançar». En este caso, la amplificación de la casuística amorosa, en las tres versiones relacionadas, conlleva una correspondencia formal extremada, cuyo matiz lúdico de divertissement cortesano no puede sino aligerar el dramatismo originario del poema» (Nider, 2001: 930). En nuestra opinión, más que de una amplificatio de las tres versiones nos encontramos ante una abreviatio de A, que pretende, además de intensificar la carga dramática del poema, aligerar el desarrollo narrativo de la historia.
} 
de ocasionar un mayor impacto estético en la pulcritud de la copia con la tachadura de todo un verso ${ }^{21}$.

Sí llevaba razón Rodríguez-Moñino cuando calificaba de torpe la labor del copista, descuidado sobre todo en lo que a cuestiones métricas se refiere, aunque muy pendiente, eso sí, de la rima. Es la única versión que sigue a rajatabla el patrón $a b a b a c d c d c$, bien porque se preocupó de regularizarla, bien porque no se apartó de la fuente que utilizara.

Por lo demás, presenta una versión muy próxima a $T$ y $M$ pero no comparte errores conjuntivos con estos testimonios, por lo que no se puede establecer ningún tipo de relación directa entre ellos. El hecho de presentar versiones similares bien pudiera ser consecuencia de que todos ellos sigan de manera más fiel la que pudo ser la versión original del poema, de la que, como ya hemos comentado, $A$ debió de apartarse deliberadamente por tener otros intereses.

\section{CONCLUSiOnes}

De acuerdo con lo expuesto, el stemma que se podría plantear para los avatares de transmisión de este texto sería más o menos este:

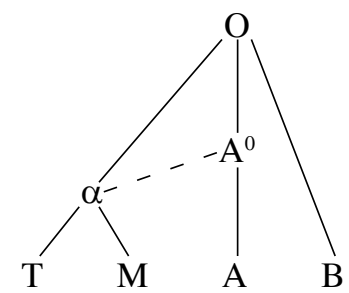

Está claro que todos los testimonios que conservamos tienen en origen la misma fuente, aunque no hay datos definitivos que nos permitan reconocer una de las versiones como la más próxima al original. Sólo el hecho de que $T, M$ y

${ }^{21}$ Este mismo proceder se observa en el v. 33 de $B$, donde dice «qu'en ser tal la ocasión» con «porquê» tachado posiblemente para corregir lo que el copista detectó como una hipermetría del verso ( $T$ : v. 33; $A$ : v. 28: «porque en ser tal la ocasión»; $M$ : om.), en el v. 209, «porque a quien Amor apenava», donde la última sílaba aparece volada y una $d$ tachada entre «Amor» y «apenava», en lo que debió de ser un «da pena», que es la lectura de $T$ (v. 239), la que a todas luces es la lectura del original porque no contiene la hipermetría de $B$, y en el v. 217 , donde dice «fue un enfermo de deseo», con «doliette» tachado -que es la variante que aparece en $T$ (v. 247)-, posiblemente en un intento por adaptar la lección al ámbito catalán, en el que «doliente» es sinónimo de 'triste, mezquino' ( $c f$. Corominas y Pascual, 1980-1991: s.v. doler). Esta palabra sólo aparece una vez más en el poema, también en su acepción de 'enfermo', pero esta vez se respeta por estar en posición de rima ( $T$ : v. $271 ; M$ : v. $31 ; A:$ v. $236 ; B$ : v. 241$)$. 
$B$ presenten versiones muy próximas entre sí - a pesar de que la collatio no revela ningún dato que permita relacionarlas de manera directa- y la estructura incompleta de $A$, que mutila el texto en la visita a los enfermos del hospital desmontando parte de la alegoría del poema, hace pensar que el texto original no debió de estar muy lejos de los testimonios de $T$ y $B$-contando con las modificaciones que Luis Hurtado y el copista de $B$ introdujeron en sus versiones-, porque $M$ también presenta una versión incompleta del texto.

Sí hay datos para suponer la existencia de un subarquetipo común a $T$ y $M$ por esa copla híbrida de estos dos testimonios de la que hemos hablado con las lecciones equivalentes de $A$ y $B$. Es síntoma de un caso de contaminación que, probablemente, no se produjo directamente con $A$ porque $T$ aparece impreso el 15 de octubre de 1557, es decir, en el mejor de los casos, unos pocos meses después de publicarse la edición del Cancionero general que incluía el Hospital de Amor. Por eso habría que suponer la existencia de esa versión manuscrita que hemos llamado $A^{0}$, que sirvió para componer $A$ y para que el copista de $\alpha$ contaminara su copia.

Por último, las tachaduras que presenta $B$, debajo de las cuales se pueden intuir lecciones que contienen los otros testimonios, demuestran que su copista no se limitó a realizar una transmisión aséptica del texto, aunque parece que fue el que menos intervino en la versión original. Nos basamos para formular tal hipótesis en que las adiáforas exclusivas de $B$ son escasas y muchas de ellas más que variantes parecen erratas de copia, porque ocasionan anomalías métricas en el verso o lecciones forzadas que empeoran el sentido con respecto a las otras versiones.

Aplicando este análisis a la cuestión de la autoría, que es el propósito principal del presente trabajo, podemos concluir que con seguridad Luis Hurtado no fue el autor de la versión original del poema. Como hizo en otros casos, el poeta toledano puso la mano en texto ajeno para modificarlo superficialmente y atribuírselo como propio. Las sospechas que podría despertar esta práctica relativamente habitual en su producción literaria quedan confirmadas en el cotejo de versiones, que demuestra la presencia de una fuente textual sobre la que trabajó el cura toledano. Tampoco pueden ser las versiones originales la del Cancionero general $(A)$ ni la del manuscrito de Gabriel de Peralta $(M)$ por las incongruencias estructurales que presentan, porque delatan la intervención mutiladora de sus autores sobre un texto previo. No tienen firma, pero conocer el nombre que hay tras estas versiones solo nos aportaría el de dos refundidores más a incluir en la lista inaugurada por Luis Hurtado de Toledo.

En nuestra opinión, es la copia con la versión atribuida a Boscán la que tiene visos de ser la más próxima al original, limpia, eso sí, de las desafortunadas intervenciones del copista. Nos lleva a esta conclusión la escasez de adiáforas que presenta y la ausencia de coplas exclusivas de la versión. 
Ahora bien, esto no significa que demos por hecho que Boscán sea su autor. La duda tiene que ver con que el Hospital de Amor no se incluya en ninguna de las ediciones antiguas que se hicieron de la obra del poeta catalán. No aparecía, por ejemplo, entre Las obras de Boscán y algunas de Garcilaso de la Vega, repartidas en quatro libros (Barcelona: Carles Amorós, 20 de marzo de 1543), una edición que controló el propio Boscán unos meses antes de morir. No fue una edición completa de sus obras, sino una selección, y la ausencia de este poema podría explicarse teniendo en cuenta que es un claro ejemplo de poesía cancioneril de tradición castellana, con un estilo poético del que Boscán se apartó progresivamente para acercarse a las formas italianizantes. En cualquier caso, también es extraño que el poema no se incluyera en ninguna de las reediciones que desde diciembre de ese 1543 y hasta 1556 se hicieron de esta obra en el taller de Martín Nucio, el mismo del que salió el Cancionero general que contiene la versión corregida y aumentada del Hospital de Amor, ni tampoco en las dos ediciones que Felipe Nucio hizo en 1569 y 1597 de Las obras de Boscán, una vez que quedó en sus manos el taller de su padre. La explicación que podría darse a esta ausencia es que la tradición manuscrita del poema debió de ser escasa si tenemos en cuenta que solo se ha conservado este testimonio de Barcelona, por lo que es probable que ninguno de los editores antiguos de la obra de Boscán tuvieran noticia de la existencia de este poema como producción del poeta catalán. Nos limitamos únicamente a esbozar la cuestión, por no contar con razones fundadas para emitir un juicio al respecto.

Sólo faltaría por ver qué hay de verdad en la atribución que hace Pedro de Cáceres al Licenciado Ximénez. Blanco (1982: 227), que da por hecho que en el origen del Hospital de galanes de Luis Hurtado está la hipotética versión de Ximénez, plantea el supuesto camino que pudo seguir el texto hasta llegar a manos de Hurtado. Y en ese viaje es parte fundamental Francisco de la Torre, el famoso poeta de nuestro Renacimiento que también fue pariente de Luis Hurtado. Nos consta que durante su residencia en Granada tuvo trato con Gregorio Silvestre, el que fuera sucesor de Ximénez en el puesto de organista de la catedral granadina y autor de las Obras en las que aparece el prólogo de Pedro de Cáceres en el que se dan estas noticias sobre la autoría del Hospital. Por eso, no sería raro que a través de este cauce le hubiera llegado a de la Torre la versión del Hospital de Amor que en alguno de sus muchos viajes a Toledo llevó en el equipaje para ponerla en las manos de Hurtado. No obstante, aun concediendo el beneficio de la duda, tampoco esto nos permitiría saber si estamos ante el autor de la versión original del poema o ante uno más de los muchos refundidores que hemos ido encontrando en el camino de este estudio. Las raíces de la tradición textual del poema están tan extendidas que, a falta de pruebas más fiables, no se puede dar con rotundidad un juicio seguro sobre la aportación del Licenciado Ximénez, si es que la hubo, al Hospital de Amor. 


\section{BIBLIOGRAFÍA CITADA}

Amasuno Sárraga, Marcelino (2000a). «Calisto, entre amor hereos y una terapia falaz», Dicenda. 18, pp. 11-49.

Amasuno Sárraga, Marcelino (2000b). «Hacia un contexto médico para Celestina: sobre amor hereos y su terapia», Celestinesca. 24, pp. 135-169.

Amasuno Sárraga, Marcelino (2004). «El saber médico tras el prólogo del Libro de buen amor: «loco amor» y «amor hereos»» en Francisco Toro y Bienvenido Morros (eds.), Juan Ruiz, Arcipreste de Hita, y el Libro de buen amor. Actas del Congreso Internacional del Centro para la Edición de los Clásicos Españoles (Alcalá la Real, 9-11 de mayo de 2003). Alcalá la Real: Ayuntamiento de Alcalá la Real, pp. 247-270.

Armas, Frederick de (1975). «La Celestina: An Example of Love Melancholy», Romantic Review. LXVI, 4, pp. 324-332.

Beltrán, Rafael (1988). «Paralelismos en los enamoramientos de Calisto y Tirant lo Blanc: los primeros síntomas del «mal del amar»», Celestinesca. 12.2, pp. 33-54.

Blanco Sánchez, Antonio (1982). Entre Fray Luis y Quevedo: En busca de Francisco de la Torre. Salamanca: Atlas.

Boscán, Juan (1991). Las obras de Juan Boscán de nuevo puestas al día y repartidas en tres libros. Ed. Carlos Clavería. Barcelona: PPU.

Boscán, Juan (1999a). Poesía. Ed. Pedro Ruiz Pérez. Madrid: Akal.

Boscán, Juan (1999b). Obra completa. Ed. Carlos Clavería. Madrid: Cátedra.

Boscán, Juan y Vega, Garcilaso de la (1995). Obras completas. Ed. Carlos Clavería. Madrid: Turner.

Boscán, Juan, Vega, Garcilaso de la, León, fray Luis de, Cruz, san Juan de la y Herrera, Fernando de (2010). Obras poéticas completas. Ed. Inoria Pepe Sarno y José M. ${ }^{a}$ Reyes. Madrid: Cátedra.

Cancionero de Estúñiga (1987). Ed. Nicasio Salvador Miguel. Madrid: Alhambra.

Cancionero de Palacio (1993). Ed. Ana María Álvarez Pellitero. Valladolid: Junta de Castilla y León.

Castells, Ricardo (1993). «El mal de amores de Calisto y el diagnóstico de Eras y Crato, médicos», Hispania. 76, pp. 55-60.

Castillo, Hernando del (1959). Suplemento al Cancionero general de... Ed. Antonio Rodríguez-Moñino. Valencia: Castalia.

Castillo, Hernando del (2004). Cancionero general. Ed. Joaquín González Cuenca. 5 vols. Madrid: Castalia.

Cátedra, Pedro (1989). Amor y pedagogía en la Edad Media: estudios críticos de doctrina amorosa y práctica literaria. Salamanca: Universidad de Salamanca.

Cátedra, Pedro (2001). Tratados de amor en el entorno de Celestina. Siglos XV-XVI. Madrid: Sociedad Estatal España Nuevo Milenio.

Clemencín, Diego (ed.) (1833-1839). El ingenioso hidalgo don Quijote de la Mancha. 4 vols. Madrid: D.E. Aguado.

Corominas, Joan y José Antonio Pascual (1980-1991). Diccionario crítico etimológico castellano e hispánico. 5 vols. Madrid: Gredos.

Crawford, J. P. W. (1922). Spanish drama before Lope de Vega. Philadelphia.

Díaz de Benjumea, Nicolás (1860). Discurso sobre el Palmerín de Inglaterra y su verdadero autor. Lisboa.

Gayangos, Pascual de (1862). Del Palmerín de Inglaterra y de su verdadero autor. Madrid: T. Fornanet.

González Cuenca, Joaquín (2004). «Introducción» a Hernando del Castillo, Cancionero general. 5 vols. Madrid: Castalia, I, pp. 26-183.

Greco, M. Elizabeth (1977). Luis Hurtado de Toledo: a Bibliographical-Critical study and edition of his Trescientas en defensa de illustres mugeres. Berkeley: University of California. [Ed. facs. Michigan: UMI, 1989]. 
Hurtado de Toledo, Luis (1557). Cortes de Casto Amor y Cortes de la Muerte. Toledo: Juan Ferrer. [Ed. facs. Valencia: Andrés Ortega del Álamo y Librería Bonaire, 1964].

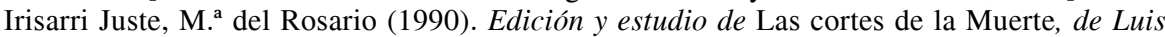
Hurtado de Toledo. Tesis doctoral inédita. Valladolid: Universidad de Valladolid.

Jauralde Pou, Pablo (dir.) (1998). Catálogo de manuscritos de la Biblioteca Nacional con poesía en castellano de los siglos XVI y XVII. 5 vols. Madrid: Arco Libros.

Lacarra Lanz, Eukene (1999). «Calisto y el «amor hereos»». Ínsula: revista de letras y ciencias humanas. 633 , pp. 20-22.

Lacarra Lanz, Eukene (2001). «Enfermedad y concupiscencia: los amores de Calisto y Melibea», en La Celestina, V Centenario (1499-1999): actas del Congreso Internacional. Salamanca, Talavera de la Reina, Toledo, La Puebla de Montalbán (27 de septiembre1 de octubre de 1999). Cuenca: Universidad de Castilla-La Mancha, pp. 193-216.

Lacarra Lanz, Eukene (2007). "¿¿Ya todos amamos?": La degradación del amor hereos en Celestina», en Eukene Lacarra Lanz (coord.), Asimetrías genéricas. «Ojos ay que de legañas se enamoran»: literatura y género. Bilbao: Universidad del País Vasco, pp. 33-76.

Lobato Osorio, Lucila (2012). «Caballeros enfermos de amor: Amadís de Gaula y Oliveros de Castilla», Tirant. 15, pp. 113-134.

Ludueña, Hernando de (1998). Dottrinale di gentilezza. Ed. y trad. Giuseppe Mazzocchi. Nápoles: Liguori.

Martin, June H. (1972). Love's Fool: Aucassin, Troilus, Calisto and the Parody of the Courtly Lover. London: Tamesis.

Mendes, Manuel Odorico (1860). Opúsculo acerca do Palmeirim de Ingalaterra e do seu autor, no qual se prova haver sido a referida obra composta originalmente em portuguez. Lisboa: 1860.

Michäelis de Vasconcellos, Carolina (1981-1982). «Versuch über den Ritterroman Palmeirim de Inglaterra», Zeitschrift für romanische Philologie. 5, pp. 216-255; y 6, pp. 37-63.

Moraes, Francisco de (2006). Palmerín de Ingalaterra (Libro I). Ed. Aurelio Vargas DíazToledo. Alcalá de Henares: Centro de Estudios Cervantinos.

Morros Mestres, Bienvenido (2009). «Melancolía y amor hereos en La Celestina», Revista de poética medieval. 22, pp. 133-183.

Nider, Valentina (2001). «De los Hospitales de amor al Hospital de neçios (de Boscán a Hurtado de Toledo)», en Christoph Strosetzki (ed.), Actas del V Congreso de la Asociación Internacional Siglo de Oro (Münster, 1999). Madrid-Frankfurt am Main: Iberoamericana-Vervuert, pp. 926-933.

Porras, George Yuri (2008). «El mal de amores y las canciones en las dos primeras «Celestinas»», Confluencia. 24-1, pp. 139-151.

Pérez Priego, Miguel Ángel (2002). «Los infiernos de amor», en Juan Casas Rigall y Eva $\mathrm{M}^{\mathrm{a}}$ Díaz Martínez (eds.), Iberia cantat. Estudios sobre poesía hispánica medieval. Santiago de Compostela: Universidad de Santiago de Compostela, pp. 307-319.

Prieto, Antonio (1991). La poesía española del siglo XVI. 2 vols. Madrid: Cátedra.

Purser, William E. (1904). Palmerin of England. Some remarks on this Romance and on the Controversy concerning its authorships. Dublin.

Riquer, Martín de (1942). Poemas inéditos de Juan Boscán. Según el manuscrito 359 de la Biblioteca Central de la Diputación de Barcelona. Barcelona: Alerta.

Riquer, Martín de (1945). Juan Boscán y su cancionero barcelonés. Barcelona: Archivo Histórico-Casa del Arcediano.

Rodríguez-Moñino, Antonio (1964). «El poeta Luis Hurtado de Toledo (1510-c. 1598)», en Luis Hurtado de Toledo, Cortes de Casto Amor y Cortes de la Muerte. Ed. facs. Valencia: Andrés Ortega del Álamo y Librería Bonaire, pp. 9-55.

Šabec, Maja (2012). «El papel de la enfermedad de amor en la Tragicomedia de Calisto y Melibea», Tropelías: Revista de teoría de la literatura y literatura comparada. 18, pp. 308-325. 
Salido López, José Vicente (2009). «Cancionero general de Hernando del Castillo», en Pablo Jauralde Pou (dir.), Diccionario filológico de literatura española: siglo XVI. Madrid: Castalia, pp. 158-163.

Salvá, Vicente (1829). «Sección de libros de caballerías en Bibliografía española», Repertorio Americano, 4, pp. 29-74.

Santillana, Íñigo López de Mendoza, Marqués de (1999). Poesía lírica. Ed. Miguel Ángel Pérez Priego. Madrid: Cátedra.

Serís, Homero (1930). «Comedia de Preteo y Tibaldo por Perálvarez de Ayllón y Luis Hurtado de Toledo: estudio comparativo de la edición príncipe», en Estudios eruditos in memoriam de Adolfo Bonilla y San Martín (1875-1926). Madrid: Facultad de Filosofía y Letras, Universidad de Madrid, II, pp. 507-533.

Vega, Garcilaso de la y Boscán, Juan (1964). Obras completas. Madrid: Aguilar.

Vera, Diego de (1625). Cancionero llamado Dança de galanes, en el qual se contienen innumerables canciones para cantar y bailar, con sus respuestas, y para desposorios y otros plazeres. Barcelona: Jerónimo Margarit.

Whinnom, Keith (1991). «Introducción» a Diego de San Pedro, Obras completas, II. Cárcel de Amor. $3^{\mathrm{a}}$ ed. Madrid: Castalia.

Wunster, Monica von (1991). Ospedali d'amore. Allegorie tardomedievali (A. Caulier e J. Boscán). Firenze: La Nuova Italia.

Fecha de recepción: 29 de mayo de 2012

Fecha de aceptación: 30 de enero de 2013 